\title{
Developing a Co-Creative Methodology of Narrative Artwork Production for the BEACONING Platform Metagame
}

\author{
Jackie Calderwood ${ }^{1}$ \\ Coventry University, United Kingdom \\ Rachael Till \\ Coventry University, United Kingdom \\ Vytautas Vasiliauskas \\ Coventry University, UK and www.vytautasart.com, Lithuania
}

\begin{abstract}
This paper presents an emergent co-creative methodology for the conception, making and sharing of narrative artwork for a gamified learning platform. Drawing on cinema, the graphic novel, and comic book art, two unusual characters were developed by Student Activators working with researchers at the Disruptive Media Learning Lab, Coventry University. The creative process began by using Clean Language and Clean Space to bring the artists' character sketches to life, and developed into a series of basic, linear and interactive narratives with original working practices. Extending this collaboration, the paper is co-authored with the two students involved. The authors reflect from their different perspectives on the Collaborative process, creation of narrative artwork and building of a series of metagames for the BEACONING platform 'Breaking Educational Barriers with Contextualised Pervasive and Gameful Learning', co-funded by Horizon 2020 programme of the European Union.
\end{abstract}

Keywords: Co-creativity, Beaconing, Narrative, Clean, Gamification

\section{Introduction}

Gamification offers teachers innovative ways to engage learners both inside and outside of the classroom through the use of digital platforms that can be accessed beyond the desktop. Addressing the potential for a pedagogy of 'anytime anywhere' learning, the BEACONING consortium has developed an integrated platform that lowers the technological barriers for teachers to author Gamified Lesson Plans (Beaconing, 2016-19). By selecting a ready-made metagame narrative and adding from a rich menu of educational minigames, teachers create a customised structure within which they can easily add their own lesson content. The metagame narrative selected, potentially plays a key part in engaging the learner, incentivising and immersing them in the learning experience as they follow this story and solve incidental educational minigame challenges along the way. The metagame needs to be both accessible to a wide target audience of learners and applicable across a range of content subject areas so that the educational mini games sit comfortably within the metagame.

This paper introduces an innovative approach to metagame creation developed at the Disruptive Media Learning Lab, Coventry University, by the authors. We reflect on the emergent co-creative methodology by which a series of metagame narratives were produced. These new narratives reference cinema, literature and the comic book or graphic novel, in contrast to the 3D avatar style of game previously available for use in BEACONING.

\section{Background}

BEACONING is an ambitious multi-faceted research and innovation action with fifteen partners across Europe (€5.9 million), running from 201619. The project draws together research institutions and specialist education agencies with games and technology companies. The BEACONING consortium is led by Coventry University ${ }^{2}$ and is co-funded by Horizon 2020 programme of the European Union ${ }^{3}$. BEACONING's objective of 'Breaking Educational Barriers with Contextualised, Pervasive and Gameful Learning' uses the problem-based learning approach to support teaching and learning of STEM subjects (science, technology, engineering, mathematics) by exploiting pervasive, context-aware and gamified techniques and technologies.

Coventry University's Disruptive Media Learning Lab (DMLL) is a semi-autonomous cross-University experimental unit with a remit to drive forward innovation of teaching, learning and practice. The DMLL offers work experience to students through the University's Student Activator scheme, administered by thefutureworks, an employment agency subsidiary company of the Coventry University Group. Student Activator positions enable students to gain valuable experience working on specific real-world projects alongside DMLL staff and bringing a fresh 'nextgeneration' perspective that may also, as in the case of BEACONING, create an insightful overlap with the target user age-group of the project.

In July 2018, in preparation for wide-scale European piloting of the BEACONING solution with students aged 10-25 years, Coventry University proposed to extend the range of metagame narratives available by producing a new series of Basic, Linear and Interactive narratives. To this objective, a small team was put together with BEACONING Researcher and media artist Dr. Jackie Calderwood, DMLL research assistant and games design supervisor Mr. Mark Lewis and two Student Activators recruited to the project. Vytautas Vasiliauskas, a final year Fine Art and Illustration undergraduate joined the team following on from his work as a Student Activator with another DMLL project. For Rachael Till, a first-year Animation and Illustration 
student, this was the first experience of employment as an artist and Student Activator. Other members of the DMLL BEACONING research group supported the team and contributed suggestions and feedback as the work progressed 4 .

BEACONING uses a bespoke Scenario Editor and Level Editor as the platform for creation of metagame narratives. This platform is currently built with Flash and intended for games developer / programmer usage only. The Level Editor is designed for 3D scene-building and the Scenario Editor presumes that a player-avatar will be the focus of game-play as the learner progresses through a series of levels (staged locations) during the metagame. Narrative plot is primarily delivered through on-screen text in the form of character dialogue in pre-constructed 'speech bubbles'.

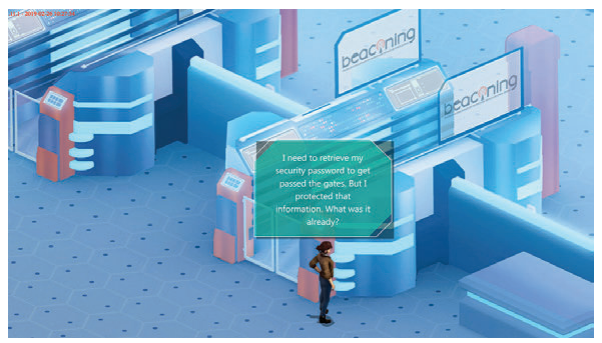

Image 1 - BEACONING metagame 'Save The Boss' with 3D environment, avatar and character speech.

\section{The Brief: Stage 1}

The proposed brief for the DMLL metagame narrative creation was to initiate a series of gameplots, or stories, using as starting point a simple default linear structure with a guiding character who would engage with, rather than represent, the player. This character might be a teacher, coach or similar and would lead the player through a series of educational mini-games in what we termed a Basic Narrative structure. Creating artwork for this Basic Narrative was Stage 1 of the Narrative Artwork Development project. Stage 2 would be a Linear Narrative in which the character's story would take precedence. Stage 3 would follow as a Non-Linear (Interactive) Narrative with a branching storyline that would offer choices to the player.

The development of the Basic Narrative needed to be completed in advance of preparations for the International Pilot, which would be led by another partner from the BEACONING consortium. The timeline also had to allow adequate time for the Researcher to learn the bespoke Editors, build, test and publish the metagame for teacher-authoring. Consequently, the Stage 1 schedule afforded a period of three weeks for concept development and Basic Narrative artwork creation by the Student Activators.

\section{Developing Characters}

Briefing meetings with the Student Activators outlined objectives for the character development, leaving options as open as possible for the Activators to bring their own creative interpretation and skills to the project from the beginning. Our objective was to create 2D artwork that could be used in the Editors to create a more cinematic style of metagame, however the craft of how to build this within the Editors had not yet been established, meaning that exact format of artwork was still an unknown.

In the first week of Stage 1, the Activators created a selection of characters responding to the prompt that the character(s) could be any gender, animal or alien, and should be a coach/guide for STEM subject learning.

The Activators each responded with originality and several characters which could have been taken forward. Activator Vytautas Vasiliauskas drew his characters on paper first with markers, as he finds this traditional way of working allows more accidents to happen, giving birth to unexpected outcomes.

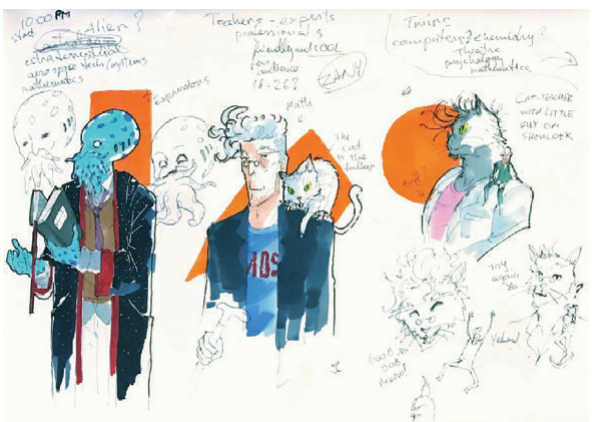

Image 2 - Character sketches by Vytautas Vasiliauskas.

Activator Rachael Till had several different characters in mind at the beginning of the project, ranging from humans, such as an engineer, to non-human characters such as an alien, a dinosaur and robots. These concepts were created digitally, as they could easily be modified and tweaked, whether that be simple colour or outfit changes. All of these characters revolved around STEM.
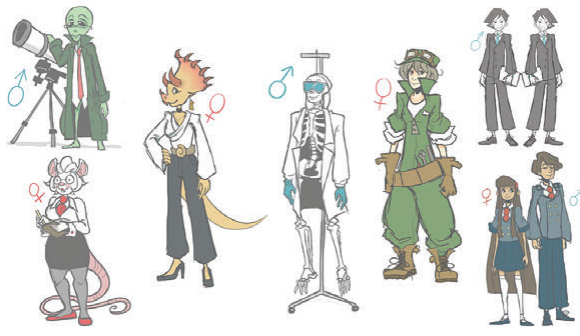

Image 3 - Character sketches by Rachael Till.

With input from the wider BEACONING team at DMLL, a consensus was reached with one of each Activator's characters chosen for further development. The alien teacher of aerospace (Image 2, left) and the skeleton lab scientist (Image 3, centre) were both seen as strong and interesting characters for development. 
Additionally, both figures have an ambiguity about their identity that the team felt would enable a diverse range of players to relate to them.

The initial idea for the skeletal figure came from hanging skeletons typically seen in science classrooms. Rachael felt that the potential of the figure's movement, in that it could only move on a frame, stood out amongst the rest of her initial designs: there was a lot of expression and character that could be explored by using this design.

\section{Developing the Landscape}

In the ethos of promoting agency and co-creating authentic voice, Activators were encouraged to take an active role in creating the narrative within which the characters would feature.

Working with uncertainty, whilst challenging, allows room for emergence, the unfolding of unanticipated opportunities, and encourages (or perhaps necessitates) creative exchange and collaboration. In practice, this requires an approach of Antifragility (Taleb 2012), in which the structure or system is able to not just survive but actually to thrive on and evolve as a result of unexpected occurrences that challenge current levels of knowledge in the status quo ${ }^{5}$. Working as a professional artist affords antifragility, for example when experimenting with a new material gives unexpected results that then becomes a process used deliberately in future. For students, antifragility could be seen as the next step into professionalism after they have built a resilient or robust set of skills through their training. Degree studies could be seen as the training to move from fragility to robustness during the course of their studies: able to withstand challenges, though not yet likely to be at a point of integrating and thriving on them out in the 'real world' beyond the pre-defined projects of the educational institution. Vytautas' attitude of 'allowing more accidents to happen' perhaps reflects his more established position as an artist already working on creative commissions beyond the University.

In order to support this transition from pre-defined to emergent process, the Researcher led a Creative Workshop for the Activators to uncover information about the world of their character, and ultimately what relationship there might be between the two characters. Using the Clean Language and Clean Space processes created by clinical psychologist David Grove (Grove and Panzer 1991) as the foundation for the workshop, the Researcher Jackie Calderwood (who has trained extensively in Clean approaches) devised exercises to elicit information about the characters and their landscapes. Clean facilitation serves to focus the respondent's attention on the features of their issue, landscape or topic of exploration, such that new rich multisensory information emerges along with unique solutions and development opportunities, through the Clean-based process of Symbolic Modelling (Tompkins and Lawley 2000). In Symbolic Modelling, the use of carefully placed Clean Language questions encourages the client to self-model the metaphors, symbols and relationality of their own system.

Whilst Clean is more commonly used to elicit information from a therapist's or coach's client about their personal metaphor landscape for the purpose of healing or self-development, it has also been shown to be an effective arts methodology for strengthening narrative development (Calderwood 2017). Emergent Knowledge was Grove's latest innovation before his unanticipated death in 2008, and works with systemslevel information to elicit new perspectives that form a springboard to a new vantage point or level of insight.

\section{Outline of Creative Workshop}

The aim of the Creative Workshop was to work with the Activators to generate ideas and create material that could be used in narrative development for the Basic, Linear and Non-Linear gameplots ready for BEACONING Pilots.

\section{Methodology:}

- Participatory design process with students in target user age-group.

- Clean techniques and approach to facilitate original expression from each participant, support emergence and gather quality information in a playful, exploratory 'lab' environment.

- Symbolic Modelling techniques to develop rich material with comprehensive exposition of 'story world' or character landscape.

\section{Objectives:}

- To develop and model a landscape for each character that includes temporal, spatial and adjacent elements as well as rich development of the character's present behaviour, attributes, abilities, interests, phobias, values etcetera.

- To explore the relationship of the elements of each character's world.

- To explore the relationship between the worlds of 2 or more characters.

- To stay Clean - allowing the individual to access a 'deeper' level of knowledge about this character, to be listened to exquisitely, having their creative exploration and expression valued uniquely, to fully develop their character from their own mind/body/ experience.

- To use Clean Space as a facilitation tool to unpack complex material and tend towards going live.

\section{Hypothesis/ Research Question:}

Clean approaches elicit rich high-quality information and facilitate emergent knowledge. Using the character as the issue to be explored, will Clean support the Activator to access or imagine the world of their character? And can material generated in this way be usable in the creation of the narrative in the gameplot? (i.e. will it provide material by developing the world such that possible narrative plots emerge?)

\section{Workshop Format:}

In the 90-minute workshop, after an introduction to the methodology and rationale of Clean, we used three exercises to develop material. Working individually with pens and paper to notate or draw responses, 
we explored firstly the symbol (in this case each Activator's metagame character), and secondly the landscape - what is happening beyond the symbol.

A third and final exercise used Clean Space to explore the landscape by physically moving to a new space and exploring the scenario of the character's world from this new space.

\section{Outcome:}

Each exercise successfully generated new and original material for each Activator about their game character. It may have been preferable to have extended the workshop into a second session for the Clean Space exercise, as both Activators were quite tired by this exercise, having worked intensely on the first two exercises. Two further planned exercises derived from additional Clean-based techniques were not used during the workshop, and could be incorporated into a second or even third stage workshop: Persona Modelling (Sullivan and Field 2016) to negotiate relationship between characters, and Systemic Modelling (Walker 2014) to resolve scenes that incorporate more than one character.

Vytautas found that the different way of exploring more about the characters' personalities and relationship allowed interesting new character traits and backstories to be unlocked.

It is not possible to draw definitive conclusions about the impact of the workshop, given that there is no comparison group and that the whole process of narrative development through Stage 1, 2 and 3 of the project embraced Activator's ideas as well as their artwork, utilised emergence and saw the Activators taking bigger and more independent roles in writing scripts and directing art-scenes as the project progressed.

However, it would certainly seem that the research questions and hypothesis proposed played a part in the successful development of the characters, their worlds and the resulting gameplots. Some specific features identified during the workshop carried forwards into the Basic, Linear and/or Non-Linear gameplots. The relationship between the characters was inevitably limited during the Basic Narrative as each had a stand-alone gameplot. In the Linear Narratives the two protagonists' relationship comes to the fore as the 'Origin Story' of each character is portrayed. And by the Non-Linear Narrative, other reasons that will be discussed later in this paper contributed to a change of relationship not only between the characters but also in the working practices of the artist Activators.

\section{Character Artwork: Creative Influences}

Following the Creative Workshop, and over the course of the weekly team review meetings, the two characters were identified as Professor Rob (alien) and Professor Tibia (skeleton). In the beginning stages of designing the Professor Rob character, Activator Vytautas chose to reference The Cthulhu Mythos (Lovecraft 1998) and Harry Potter (Rowling 1997). Vytautas, a Lithuanian architecture graduate who came to the United Kingdom as a mature student, to study for his second degree, also drew on the general look of a professor in England as he had seen or imagined it. The personality of Rob came from writing stories about him, discussing both of the characters with the team, and "just letting Rob himself reveal who he is to me".

In contrast, at the start of the project Activator Rachael's design process was influenced primarily by the field of STEM and what was associated with it. For example, astrology is linked to STEM, and aliens are often associated with space, so it seemed logical to design an extra-terrestrial character. This ensured that, thematically, STEM always stayed at the root of the project.

\section{The Basic Narrative Metagames}

As the characters developed so did the understanding of how the artwork could be utilised within the Level and Scenario Editors. Through a process of dialogue between the platform Developers, Researcher, Activators and DMLL BEACONING team, a protocol was agreed for Basic Narrative artwork, used to create two separate metagame gameplots, one for each character. These gameplots each feature just one background scene: Rob's teaching room (in the castle that emerged during the Creative Workshop) and Tibia's lab.

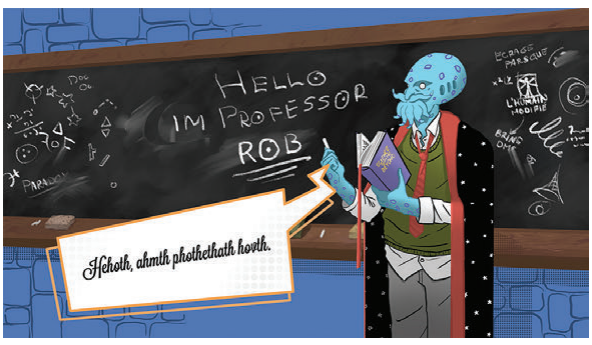

Image 4 - Professor Rob artwork in development with alien speech.

Each character then consists of a number of iterations in different poses with different expressions. In the process of programming the metagame gameplots, Researcher Jackie, identified an opportunity to provide alternate responses after each educational mini-game slot, dependent on the pass/ fail result of the player with that mini-game. As a result, the Basic Narratives offer the player three attempts at each mini-game before they progress to the next minigame. The guiding character gives a different facial expression, gesture, and text speech response, for a pass, first-and-second-time fail, or for a third-time fail. To work efficiently in the timeframe allowed, the Activators developed kit parts for their character, a strategy re-used later in the Non-Linear Narrative as an efficient time-saving innovation. Subject to further development the kit parts could also be used to script animation of the characters for future gameplots. 


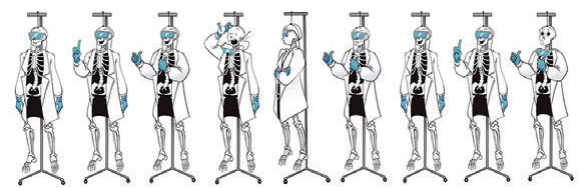

Image 5 - Professor Tibia Expressions for Basic Narrative.

The Basic Narrative development process demonstrates evolving complexity with the triple play option emerging in response to working with the Level and Scenario Editors. The script for the character speech was written to utilise the existing text and speech-bubble options of the platform. Character speech embodies some of the characterisation that emerged during the Creative Workshop, for example the alien language spoken by Professor Rob is conveyed through ad hoc capitalisation of his speech. Each Professorial character is presented as friendly guide/coach encouraging the player to complete all mini-games and return again in the future, although Tibia presents as an open supportive coach whereas Rob has a more contentious personality.

The Basic Narratives proved very successful for partners during the BEACONING Pilot, quickly attracting requests for versions in Turkish and French languages. Also, for a 'Step 2' Basic Narrative with each character, in which the same artwork and structure is used, but a second stage of character speech acknowledges the returning player and provides a different commentary.

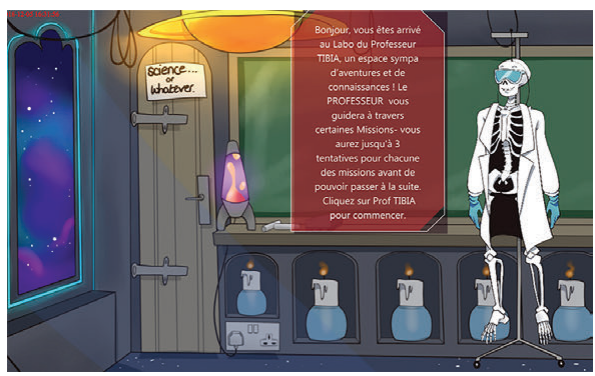

Image 6 - Professor Tibia Basic Narrative, French Welcome Screen.

\section{The Brief: Stage 2}

With the Basic Narratives already in use on the BEACONING platform, Stage 2 of the metagame narrative artwork project launched with a seven-week timeline for development. The objective of this stage was to advance development of the BEACONING gameplay with the addition of a linear storyline. As both Activators now had a working knowledge of the design process required, and had established the agency of their character and its world, this second stage springboarded the Activators into the role of author as well as artist. The scenario (character as straightforward guide) was prescribed for the Basic Narratives, and the character text written after the artwork was created and before the game-build, by the Researcher. In Stage 2, the Activators were offered freedom to develop a scenario based on their character, alongside the new challenge of writing character speech. Within this narrative freedom was the caveat that, where possible, mini-games should be tied to the storyline in a natural feeling manner; for example, something may be locked away in a cupboard and the player could be asked to discover a code to unlock it. As part of the development process, Activators were instructed to storyboard their narratives to provide a better understanding of how they will look and flow. High quality images for use in-game would then be created based on the agreed storyboards.

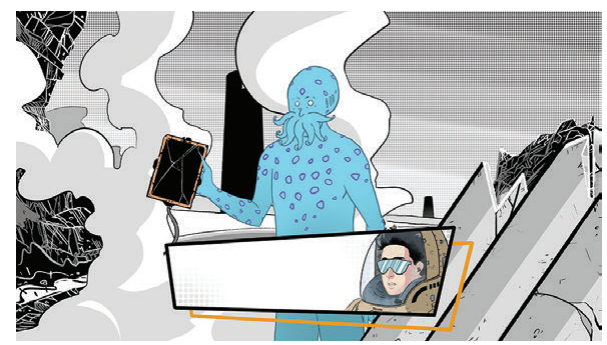

Image 7 - Integrating minigame play: the tablet, Tibia's Origin Story.

Activators Rachael and Vytautas came up with the interesting twist that they would work on the backstory of each other's character - Rachael creating the storyline of Professor Rob's Origin Story and Vytautas creating that of Professor Tibia. Taking on each other's character also necessitated a blending of artwork styles, and ensuring consistency across the two narratives in terms of style and structure for teacher-authoring and for player ease. After further experimentation with the Level and Scenario Editors, the team decided to take a fresh approach, and integrate the character into the background, creating more of a comic-strip narrative with each new frame depicting a scene from the narrative. The Researcher also worked with the Editors' Developer to take a different approach to speech, as it was felt that the aesthetics could be improved by creating speech bubbles and text within the artwork rather than overlaying the default text boxes in the Editor. This back-and-forth between game-build and artwork creation meant that all members of the team were balancing the opportunities of emergence with the constraints of re-appropriating a beta technology platform. Meanwhile, new technologies appeared in the artwork, in the form of Tibia and Rob's Holobot ${ }^{\mathrm{TM}}$ used to signal to the player, the advent and the completion of an educational mini-game. 


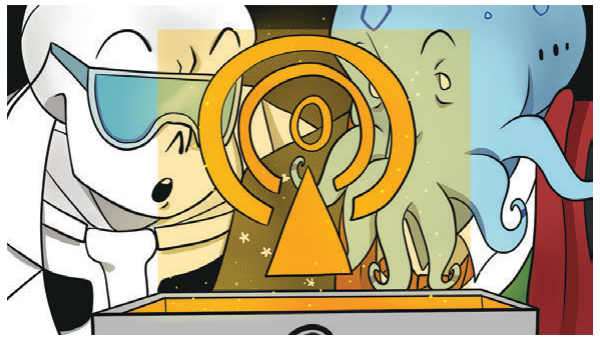

Image 8 - Integrating minigame play: Holobot ${ }^{\mathrm{TM}}$, Rob's Origin Story.

\section{Co-creating Narrative Aesthetics}

Literature, film, comic books and games have been key long-term influences on Activator Vytautas' work.

Both Vytautas and Rachael found they had a shared interest in graphic novels and comics. With the brief for Stage 2, Vytautas proposed to have the backgrounds black and white with characters being in full colour, thus allowing them to 'pop'.

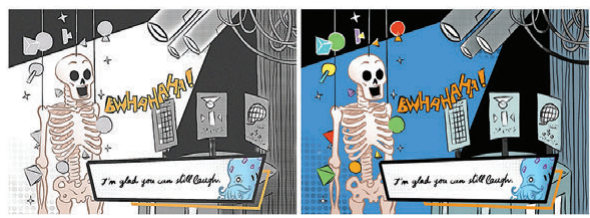

Image 9 - Background proposals for Linear Narrative.

While drawing backgrounds, Vytautas used BenDay dot textures (Day 1905) to increase the stylisation and the comic book feel.

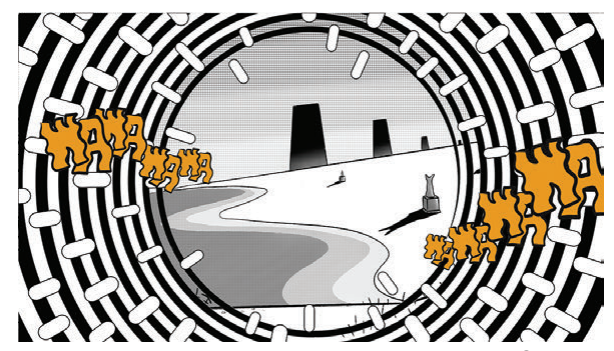

Image 10 - Artwork with Ben-Day dot textures, Tibia's Origin Story.

Aesthetics for the final pieces developed in hybrid from the ideas of each of the Activators, for example the character speech bubbles that combine a graphical quality to make them stand out and which contain a selection of character expressions to augment the character text.

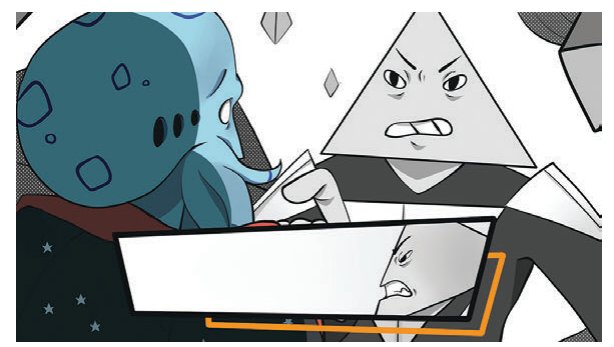

Image 11 - Professor Rob's Origin Story, Linear Narrative Artwork.

\section{Collaborative Process}

The two Activators already had practices in place that reflected their different backgrounds in animation and fine art, as well as their common ground of illustration. Activator Rachael worked in a far quicker, less detailed manner typically digitally, whilst Activator Vytautas worked slower, typically traditionally, however produced much more detailed work.

Activator Vytautas reflects that at the start of the project he worked predominantly by himself. His working practices were to develop a routine based around his life style and the deadlines that needed to be met. The routine evolved as the project went into the next stages, in particular with the opportunity for writing narratives about Rob and Tibia. The two Activators started communicating more and more about their ideas and where to take the characters. During weekly meetings they talked in person and presented what they had done over the past week to the team. At other times they continued brainstorming and sharing ideas by chatting online. During Stage 2 of the project the Activators agreed to create Origin Stories as the first stories to be told, and to switch their respective characters, Vytautas developing the back story of Rachael's character Tibia, and vice versa. Vytautas describes this switch as 'opening new doors, adding depth to the characters and adding a new level of interest and fun to both of us'. This switch also encouraged communication between the Activators as they consulted each other for ideas and solutions whilst working on the stories.

Activator Rachael reflects on several stages of involvement during the practical creative process. Creative work for Rachael initially starts out as a mind map, or just rough notes, which are then translated into extremely rough sketches. For this project, those sketches were then reviewed by the team. Feedback would be taken into consideration and translated back into the designs before being finalised. Character design came first, followed by writing the script for the stage. After the script was reviewed and finalised, thumbnails of each potential screen could be created, which would then be worked up into more detailed sketches, before being completely finalised. The text box assets and text would then be added to each screen. 


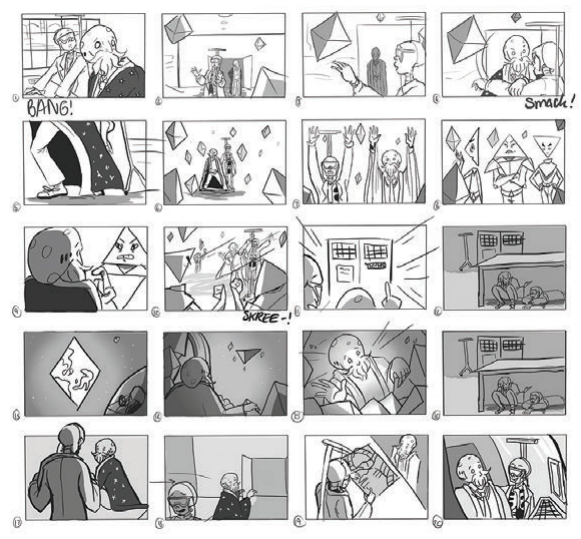

Image 12 - Storyboard, Rob's Origin Linear Narrative.

\section{The Brief: Stage 3}

For this final metagame narrative, the team decided to focus production on one gameplot that would include the now familiar Professors, Rob and Tibia, and may introduce additional characters. The brief provided to the Activators outlined that Rob and Tibia should come across as empowered problem-solvers, reflecting the more sophisticated level of engagement by learners with the STEM-oriented mini-games. Learners may have already played the Basic and/or Linear Narratives, and teachers could be encouraged to build more demanding educational challenges into the minigames of this third (interactive narrative) progression of the gameplay. The interactive narrative may reference the Basic and Linear Narrative content, but should also work clearly as a standalone for learners who have not played the earlier games. All learners should have the opportunity to play all mini-games the narrative branches would need to be designed with this imperative.

The Non-Linear Narrative took the collaboration and co-creativity of the team to another level. We challenged the Developers of the Scenario and Level Editors to create a new format for text. In response to demand from partners across Europe to have the new Linear Origin stories translated into their own languages, the Developers and Researcher created a Multilingual menu so that the gameplots could be played in Romanian, Turkish, French, Spanish, Italian or English. Part of this process meant removing the text from the artwork speech bubbles, and overlaying the text programmatically through the Scenario Editor. In the Non-Linear Narrative, an extra feature was added so that the different characters 'speak' in different coloured text.

However, as with the Basic and Linear Narratives, the first stage was back to the drawing board to construct character sketches and storyboards whilst narrowing down the expanded choices offered by an interactive narrative.

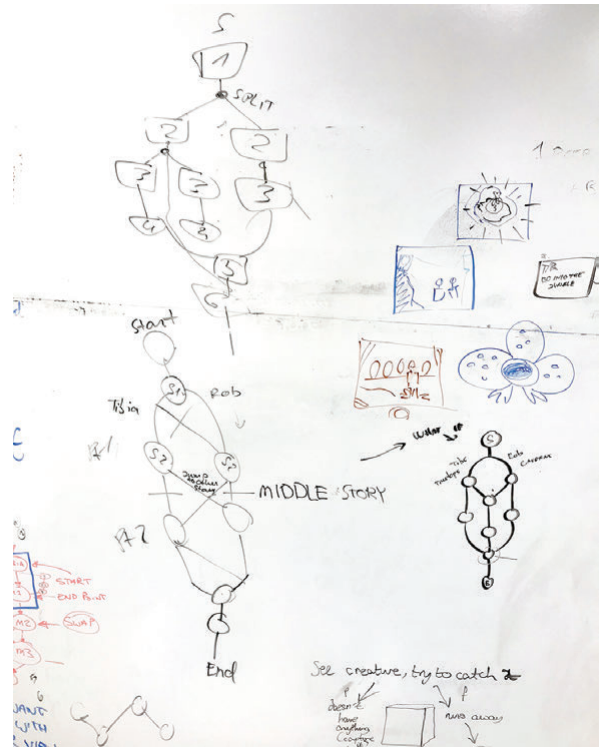

Image 13 -Team brainstorm on interactivity. Whiteboard sketches.

The initial two-month timeline proposed for Stage 3 was soon looking over ambitious, given the complexity and scale of the emerging narrative, still only at story board stage. In order to work around the possible loss of one of the Activators after graduation, we proposed a new creative approach: Activator Vytautas would create the backgrounds, and Activator Rachael would create the figures, text boxes and complete the character speech.

As it transpired, we were fortunate to keep both Activators working on the project and to extend production by a further 6 weeks, with an intense focus on completion for the final month.

Activator Vytautas reflects that they had a rough idea of the workload requirement that could be needed for this stage, strengthened by their experience and understanding of each other's strengths and weakness. Vytautas enjoyed the new challenge of writing the backstory for the piece whilst Rachael storyboarded. They brainstormed together on problems encountered.

Rachael reflects that the allocation of creative tasks worked extremely well in the Non-Linear narrative. Vytautas created intricate, detailed alien backgrounds that really brought the world to life, whilst Rachael was consistently drawing the characters for several frames, on the same background quickly. Vytautas focused greatly on bringing the world to life, while Rachael focused on bringing the characters to life - each playing to their particular strengths and interests.

The two Activators would call one another via Skype and draw on calls. Sketches and visual ideas would be passed back and forth during these calls, which would last for a few hours at a time, and, often, the best ideas for the progression of the artwork 
would come from these calls. Character designs for both Biemie and the Mother Beast were finalised in this way. Skype was used consistently throughout the project: files would be dropped into the chat, including artwork and narrative documents, and the two Activators would call one another if they had an idea or concern about the project.
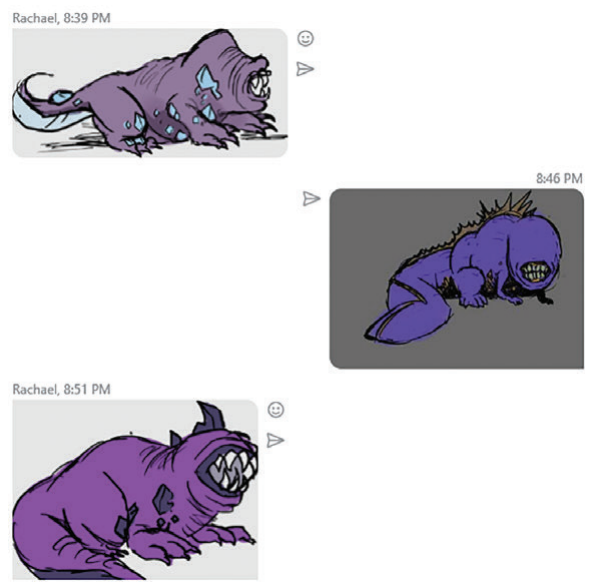

Image 14 - Collaborative Design, Mother Beast. Screengrab, Skype.

Activator Rachael observed that the Non-Linear Narrative drew together everything the Activators knew about comics, from laying out the screens, the thumbnailing to the final product. In addition to this, they took a lot of inspiration from science fiction movies that they both liked for this stage and incorporated these elements into the story to create something new. This stage possessed the most outside influence in comparison to earlier stages. For example, the Tsar character was inspired by characters such as 'Terminator' and the 'Predator', as both Activators liked the idea of some greater unrelenting force hunting the two main characters.

Activator Vytautas reflected that during the whole project, he had to refine his creative process and practices more and more as the demand for work increased by a big margin with each new production stage introduced. In the beginning Vytautas struggled to draw fast as he loves detailing and perfecting everything. So, for this project he had to develop a new art style and streamline his way of working. By the end he managed to create artworks at 'a decent pace' and at a quality that he could be proud of.

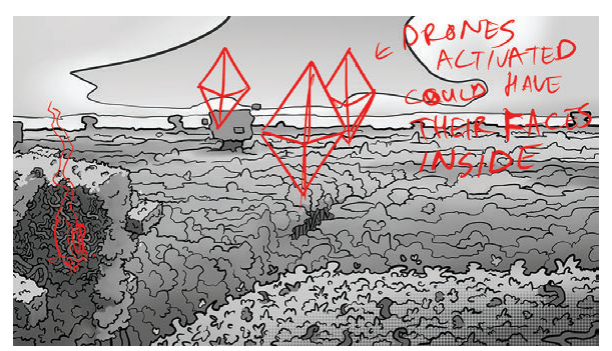

Image 15 - Non-Linear Narrative, Background with Art Notations.

Activator Rachael concludes that meeting deadlines was crucial. Time had to be managed far better during the final stage of the Non-Linear narrative. As the Activators were tasked with creating the artwork within a specific, non-negotiable deadline, that deadline really pushed them to achieve the result quickly. Rachael feels that this push really allowed them to achieve their best work.

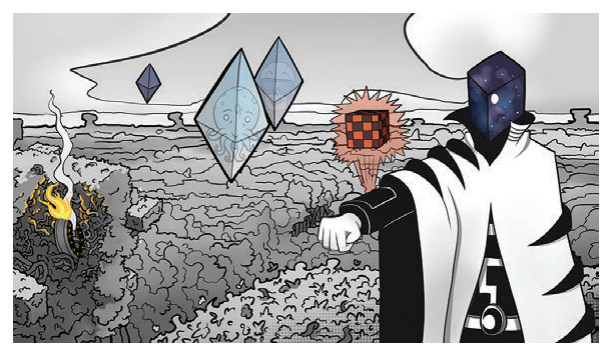

Image 16 - Non-Linear Narrative, Finished Artwork, Tsar, Drones.

\section{Impact: Activators}

Vytautas, now graduated and working as an advertising designer in Lithuania, has found that the style he created has stayed with him, whenever he needs something done that is sufficiently detailed yet has a finished, graphic and comic look. He feels that whenever he works in this style he continues to improve and refine it as needed.

Rachael reflects that although she works similarly for coursework, working on this project has really consolidated her creative process, and it has really helped with her University studies. She feels that she now approaches work in a far more professional manner, and manages her time far better than she did before working on the BEACONING project. Rachael is now in her second year of undergraduate studies, and is already working on two more projects with the DMLL at Coventry University in her continuing role as a Student Activator.

The most successful aspect of the work, in Rachael's opinion, was creating a universe in which Rob and Tibia exist. By the end of the project, in the Non-Linear stage, she felt that they had built up a real place for the protagonists to exist, filled with its own characters 
and worlds. They had been working with the characters closely for months, and had added other characters, creatures, and places for the pair to interact with. Rachael hadn't been able to work with a character for such an extended period before, and found it a very useful experience, especially as she envisages that in the future she may work with a character for an even longer timeframe.

The lessons learnt during the project were the most important and successful aspects to Vytautas. Equally important for him were the fact that the project was successfully finished and the final deadline met, which brought joy, great satisfaction and validation to the labour and the hours that were put in. All of these elements were both challenging and rewarding.

\section{Reflection on the Collaborative Process}

Activator Vytautas found the collaborative process with Rachael to be a very good experience, remarking that they worked well solo and together. Both put forward ideas and voiced concerns over them. From drafting storyboards to writing narratives, to designing new characters and creating final assets and frames of the stories - all was discussed, talked about and explored. Vytautas found that it was similar working with Jackie and Mark both during the regular meetings and outside them. Vytautas learned a lot about the nature of such a project and what is needed for it to be realised. He felt that he took away a lot of good personal and other lessons from the whole time working at the DMLL. He also met and befriended many wonderful people working there. It was a great environment to create in. Vytautas understood the great value of communicating one's thoughts well to others and taking criticism better, as it is all for the greater good of the project. Also, he learned to meet deadlines more efficiently and be more reliable while doing so, which led to better thought process and planning and also faster production. These lessons made him more prepared for future team collaborations as the work flow beats are similar in all kinds of environments, be it cinema or animation, making a comic book or drawing storyboards.

On reflection, the art style created and process learned has consolidated through the completion of the final interactive narrative. The team worked well together, and the artists were 'pushed' into various new directions and thought processes. Any 'crunch time' that arose became a good opportunity to solve challenges by finding new solutions. The only thing that Vytautas reflected that he would change would be to have even more time and more work, as it was a great joy working on the BEACONING metagame project as well as interacting with the fun people at the DMLL.

Reflecting after the project, Rachael observed that there was a great deal of collaborative work involved. This began with the Basic stage, in which the two characters had to link only by existing within the same Universe. The Activators had to keep an overall general aesthetic, however, which came from agreeing on several aspects: the way the text box would look, the overall colour scheme, the font and size. This ensured that all the narratives would appear part of the same set. Working in the DMLL environment made working on the project extremely easy: ideas could be bounced between different people fluidly. The team planned out the Non-Linear narrative using the large white board at the back of the DMLL, a wide space that was easy to work with. Having an allocated meeting every week where artwork would be discussed ensured that the artwork progressed smoothly and was a great way for everyone to give their opinions.

Although collaboration was useful and worked well in the creative process, it could sometimes be difficult for the two Activators to agree on topics artistically and narratively, which could be challenging. In some cases, they both had opposing ideas that they would both have to find middle ground on or propose the ideas to the DMLL team to settle the matter.

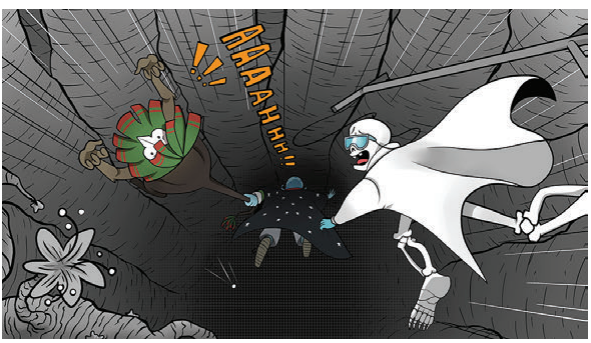

Image 17 - Non-Linear Narrative, Finished Artwork, Tibia, Rob and Katmonkey Falling Underground.

Reflecting back, if Rachael could start the project from the beginning, she would have ensured that the Basic, Linear and Non-Linear narratives linked more closely. Rachael feels that there is somewhat of a disconnect between them. In the Basic Narrative, the two characters are planned to be in an environment reminiscent of school or a University. However, the narrative that surrounded them completely changed in the Linear Narrative. The more narrative work we did with the two characters, the more an expanded universe was created, that Rachael wishes could have been explored more with from the very beginning. In addition to this, the Non-Linear narrative should have been planned out more thoroughly from an earlier stage. This stage was extremely weighted, and the story was very complex in comparison to the previous stages. Retrospectively, Rachael would have planned out the Non-Linear narrative far more effectively, with better time management. She also believes that it could have been more consistent artistically if both Activators had worked on each stage in the same creative way they did for the Non-Linear narrative; the collaboration between them created a unique art style that stands above the other narratives in Rachael's opinion.

If Rachael were to do this project again, she would most definitely keep the characters of Professor Tibia and Professor Rob the same. Both characters work extremely well together as a duo, and they were easy to write for: they clicked together both visually and narratively. Rachael thinks that the overall artistic direction, with the black and white backgrounds and 
characters in colour, works extremely well and really makes the characters pop. Rachael would keep the story of the Non-Linear Narrative the same: and is really pleased with the work on it.

\section{Impact: Gamification}

The two Basic Narratives featuring the Professor Tibia and Professor Rob characters have proven popular with BEACONING partners in the large-scale pilots which have engaged with over 6000 students and teachers, spanning Primary, Secondary and Higher Education, across and beyond Europe.

For teachers engaging with the BEACONING authoring platform to create their own Gamified Lesson Plans, these metagames provide an easy-touse structure to customise by adding their own choice of educational minigames and learning content. The metagames are quick to test and, in some cases, teachers have made use of the characters by referring to them in the minigames, thus creating a link between the minigame and the overarching metagame narrative.

Further research has been conducted into the reception of the characters and the narrative structures, that affirms players' reception of the characters as a teacher or guide, and shows that the artwork is considered to be original, creative and of a high quality. As yet, there is insufficient data to establish the extent to which the narratives support immersive learning (experienced through the educational minigames) or whether they distract the learner from the task at hand. Authoring skill of the teacher making the Gamified Lesson Plan is likely to play a major role in this - the extent to which the minigame customisation makes use of the metagame narrative is dependent on the teacher's versatility and skill in creating an endogenous blend.

The BEACONING consortium have adopted the characters for use in promotional materials. The 'Professors' now feature on roller banners, business cards and fliers that have been distributed at exploitation events across Europe - giving the Activators' work wide exposure.

Potentially the most significant impact of these Basic Narratives lies within the domain of co-creativity. As discussed above, development of the Basic, Linear and Non-Linear Narratives by the Coventry University team has, at each stage, led to development of new features within the Level and Scenario Editors. Other BEACONING partners have taken inspiration from the Professor Rob and Professor Tibia narratives to work towards re-use of this structure, with new artwork relevant to their own context - for example, Vlad the Impaler, a historical figure from Romania (Stefan et al. 2019). The partner responsible for BEACONING's initial $3 \mathrm{D}$ avatar metagames has, in response to popularity of the Basic and Linear Narratives, created several new Basic-style gameplots with a range of assets that could be readily re-appropriated. The inspiration for this change of approach is both the series of narratives produced and the model of co-creative collaboration established at the DMLL. The library of assets for reappropriation would support a future potential model of BEACONING metagame production. This would be envisaged as a professional work environment in which Student Activators gain experience as programmers, artist-illustrators, creative writers and game designers, working together to deliver metagames commissioned for specific curriculum areas and/or learners and learning content.

\section{Conclusion}

Re-appropriation of the BEACONING Level and Scenario Editors for 2D cinematic and comic inspired artwork proved to be not only workable in creating a series of Basic, Linear and Non-Linear metagame narratives, but also has inspired the addition of new features within those Editors, and a fresh approach by other consortium partners.

The engagement of the two Student Activators on the project brought fresh ideas appealing to the target audience. Both Activators rose to the challenging opportunity of working as part of a professional team, with the need for communication, collaboration, high quality outputs, reliability and meeting tight deadlines, that this involves. In return, they developed new skills and practices that contributed to the artwork created and have also already transferred into their work (and studies) beyond the project. The team had to work with a positive and antifragile approach in order to meet (and exceed) our objectives of this innovation action, whilst negotiating the previously untrodden terrain of creating BEACONING metagames with a 2D frame-byframe mode of storytelling.

The Clean ethos introduced explicitly in the Creative Workshop laid a foundation for the Activators to learn from and explore the world of their character, to support the creative emergence of new information, and to respond to this with curiosity, growing communication skills and a good level of collaboration. The flow from Basic to Linear to Non-Linear is reflected in the working process developed and in the building of the metagames in the Level and Scenario Editors. For such a flow to be reflected across different aspects of the project is itself an indicator of congruence within the 'learning system' or symmathesy ${ }^{6}$ of the project as a whole. as it works to overcome difficulties and to find resolution and even inspiration through acceptance of difference, to the point where each vitae (part of the system) is contributing, learning and growing simultaneously as an autonomous individual and as a part of the whole.

For the Research team at the DMLL, the project has been a real success, in terms of immediate outputs and benefits, and also as a model of practice to potentially take forwards within the BEACONING approach.

\section{Endnotes}

\footnotetext{
${ }^{1}$ Dr.

2 BEACONING is led by Professor Sylvester Arnab, Professor of Games Science and Applied Innovation Lead at the Disruptive Media Learning Lab, Coventry University, UK.

3 BEACONING is co-funded by the Horizon 2020 Framework Programme of the European Union under Grant Agreement 687676.
} 
4 The authors would like to acknowledge Professor Sylvester Arnab for the original brief for the metagame narrative development and for ongoing support and critique, as also from BEACONING Research Fellow Dr Michael Loizou and Applied Innovation Senior Project Manager Mrs Jane Beaufoy.

${ }^{5}$ Taleb refers to such events as 'Black Swan' events referring to the paradigm shift that occurred when explorers reported sighting of black swans at a time when all swans were believed to be white by definition.

6 Nora Bateson's term 'symmathesy' reclaims the systems thinking of her father Gregory Bateson and the early Cyberneticists, as a living process. She defines symmathesy as the 'process of' and/or 'entity formed over time - by contextual mutual learning through interaction'. Nora Bateson uses the term vita/vitae for the 'parts' of the 'system' which she defines as 'any aspect of a living entity that, through interfaces or learning, forms a larger living entity or symmathesy' (Bateson 2016). Institutions, organisations and teams of people are all considered to be examples of living entities in this definition of vitae and symmathesy.

\section{Bibliography}

Bateson, N. 2016. Smaller Arcs of Larger Circles, framing through other patterns. Axminster: Triarchy Press.

Beaconing. 2016-19. Breaking Educational Barriers with Pervasive and Gameful Learning. Website: Advanced Technology Systems. https://beaconing.eu/. Last access on $28 / 05 / 2019$.

Calderwood, Jackie. 2019. "Development of a Research Protocol for Teacher Engagement in the Coventry Pilot of the BEACONING Platform for Anywhere Anytime Gamified Learning". Communication presented in IV International Congress Communication and Thought: Emerging Communication, Universidad de Sevilla. Spain, 10-12 April.

Calderwood, Jackie. 2017. Pervasive Media and Eudaimonia: Transdisciplinary Research by Practice. Doctoral Diss. De Montfort University.

Day, Benjamin. 1905. How to work it: a manual for the use of the Ben Day rapid shading mediums and its registry attachments. New York: Benjamin Day.

Grove, D. and Panzer, B. (1991) Resolving Traumatic Memories: Metaphors and Symbols in Psychotherapy. New York: Irvington Publishers Inc.

Lovecraft, H.P. and others. 1998. Tales of the Cthulhu Mythos. New York: Ballantine.

Robin, B.R. 2016. "The power of digital storytelling to support teaching and learning." in Digital Education Review 30:17-29.

Rowling, J.K. 1997. Harry Potter and the Philosopher's Stone. London: Bloomsbury.

Ștefan, I. \& A., Baalsrud Hauge, J., Calderwood, J., Beaufoy, J., Arnab, S., Loizou, M. 2019. "Story-Oriented Learning". Communication presented in The $15^{\text {th }}$ International Scientific Conference eLearning and Software for Education, Bucharest, Romania, 11-12 April 2019.

Sullivan, W. and Field, P. (2016) Persona Modelling London: Clean Change Company \& Clarity of Purpose Ltd. Taleb, N. N. 2012. Antifragile: How to Live in a World We Don't Understand. London: Allen Lane, Penguin.

Tompkins, P. and Lawley, J. (2000) Metaphors in Mind: Transformation through Symbolic Modelling. The Developing Company Press.

Walker, C. (2014) From Curiosity to Contempt: Creating the Conditions for Groups to Collaborate Using Clean Language and Systemic Modelling ${ }^{T M}$. Fareham: Clean Publishing. 